\section{Orofacial Injuries in Children and Adolescents (2009-2013): A 5-Year Study In Porto, Portugal}

Humberto Gomes Vidal ${ }^{1,2}$, Inês Morais Caldas ${ }^{3-5}$, Luiz Gutenberg Toledo de Miranda Coelho Júnior ${ }^{6}$, Eliane Helena Alvim de Souza ${ }^{6}$, Marcus Vitor Diniz de Carvalho ${ }^{6}$, Evelyne Pessoa Soriano ${ }^{6}$, Maria Lurdes Pereira ${ }^{3,7}$, Arnaldo de França Caldas Jr6
'Department of Legal Medicine and Forensic Sciences, Faculty of Medicine, UP - Universidade do Porto, Porto, Portugal

${ }^{2}$ Dental School, Arcoverde Campus, UPE - Universidade de Pernambuco, Arcoverde, PE, Brazil ${ }^{3}$ Faculty of Dental Medicine, UP Universidade do Porto, Porto, Portugal ${ }^{4}$ Center of Forensic Sciences (CENCIFOR), UC - Universidade de Coimbra, Coimbra, Portugal ${ }^{5}$ Centre for Functional Ecology (CFE), Department of Life Sciences, UC - Universidade de Coimbra, Coimbra, Portugal ${ }^{6}$ Dental School, Recife Campus, UPE - Universidade de Pernambuco, Recife, PE, Brazil ${ }^{7}$ Public Heath Institute (EPIUnit), UP Universidade do Porto, Porto, Portugal

Correspondence: Arnaldo de França Caldas Jr., Avenida General Newton Cavalcante, 1650, 54.756-220, Camaragibe, PE, Brasil. Tel: +55-81-99971-3652. email: caldasjr@alldeia.com.br

Key Words: orofacial injuries, children, adolescents, violence

\section{Introduction}

Since 1996, the World Health Organization (WHO) has considered that, all over the world, violence is one of the major public health problems that affects all countries and societies without distinction, regardless of victims' age or gender (1). According the WHO, violence is any act or action characterized by the intentional use of physical force against or power over third parties, resulting in injury, death, psychological harm, deficiency in development or deprivation (1). Violence can be classified into the following categories: it may be physical, psychological or sexual, and can involve financial abuse, neglect, abandonment or selfneglect (1). Physical abuse can be defined as the intentional use of force or implements against an individual that causes, or has the potential to result in physical harm (2).

Child abuse has been studied worldwide $(1,2)$. However, it is difficult to know its real prevalence, since cultural, legal, conceptual and methodological differences in the studies conducted, together with under-reporting, hinder its real measurement in different countries $(3,4)$. In Portugal, as in other countries, since the true prevalence of the problem is not known since many cases are never reported. Nevertheless, every year the Commission for Protecting Children and Young People at Risk (CPJCR) (5) monitors thousands of cases of child victims of abuse ensuring that every case of aggression is properly registered and investigated.

It is estimated that $85 \%$ of physical acts of aggression against children concern the head, neck and the face (6). Nevertheless, it must be considered that some injuries, like those on bony prominences in children who walk independently, may be due to accidents (7). However, symmetrical lesions with recognizable patterns, peculiar shapes, sharp edges and/or with repetitive features are strong indicators of child abuse (8-10). Some possible physical signs of child abuse are bruises, bite marks, burns, lacerations and bone fractures (11). In a 2007 cross-sectional study in Portugal, it was observed that $11.6 \%$ of injuries resulting from voluntary violence were related to orofacial trauma (12). According to Darche et al. (8), injuries arising from child abuse involve face and skull in 78\% of cases. These lesions are usually inflicted by the perpetrator's hands, objects, or happen secondarily as the result of falls. Craniofacial fractures in children, although rare, can be very serious (9).

Health professionals have an important role in identifying and reporting violence victims to the authorities. In many countries, health professionals are required by law to report cases of abuse (13), and dentists can play an important role in identifying and reporting situations of 
violence, since, as stated before, most injuries arising from such violence concern the head and face areas. Despite this, many dentists do not report cases of suspected child abuse. The reasons given are diverse and include fear of losing patients, low level of confidence in child protection services, fear of dealing with parents, the uncertainty of the diagnosis and not knowing the proper way to handle these cases (7).

Moreover, health professionals and institutions can play a key role in producing and disseminating information on preventing violence and promoting health (14). Not only children who are victims of abuse, but also their families, should receive appropriate care in order to prevent the perpetration of further violence (15). These actions may reduce the risk of a continuously expanding cycle of aggression which, in some severe cases can lead to the death of the victim (16). This study sets out to identify orofacial injuries among children and adolescents, victims of physical aggression, referred for examination at the INMLCF-DN.

\section{Material and Methods}

This study was conducted in Porto, Portugal. Case reports, held in the Medlegis data archives system of the National Institute of Legal Medicine and Forensic Sciences - North Delegation (INMLCF-DN) were used on instances of physical violence against children and adolescents (PVCA). The range of actuation of the INMLCF-DN covers eight cities (Gondomar, Porto, Maia, Matosinhos, Póvoa de Varzim, Valongo, Vila do Conde, Vila Nova de Gaia) and benefits $1,118,517$ inhabitants. Reports referred to a five-year period (2009-2013), and concerned victims aged 0-17 years old. Information on region of orofacial injuries, sex and age of the victim, data on the alleged aggressor and year of occurrence was recorded, as well as the lapse of time from the aggression to the examination moment.

Instances of aggression to the head, face and neck were subsequently analyzed and cross-referenced to children and adolescents aged up to fourteen, and from fifteen to seventeen years old and they were also cross-referenced to sex. The criterion for inclusion was any and all cases in which forensic tests carried out by INMLCF-DN professionals had confirmed causal link. Inconclusive cases were excluded. Frequencies, standard deviations and medians were calculated. The number of injuries to the head, neck and face was cross-referenced to the covariables sex and age (0-14 and $\geq 15$ years) by means of Chi-squared test or Fisher's Exact test, with a margin of error of 5\% (SPSS 22; SPSS Inc., Chicago, IL, USA).

\section{Results}

During the five years period, 2148 complaints were recorded. After applying the inclusion and exclusion criteria,
1380 cases of PVAC were confirmed. Of the 768 cases excluded, 561 showed no correspondence between the clinical examination to confirm the injury to the complaints (clinical nexus) and the alleged injuries, while 207 were classified as inconclusive because the investigation had not been concluded.

Most victims were male (56.4\%), with a mean age of 13 years (Standard Deviation $(S D)=3.914$ ); the median age was 15 years, 2009 was the year with the highest number of occurrences. $56.5 \%$ received medical attention after the act of aggression, and 79.6\% were first-time victims (Table 1).

It was found a total number of 3019 injuries. On average, each victim was struck 2.18 times. Injuries to the head, face and neck totaled 1383 lesions, 46.34\% of all injuries (Table 2).

On referring in particular to the analysis of the regions of the face, head and neck, the face was the region that was most affected [33.2\%], followed by combined injuries suffered by the same victim to the head and neck (Table 3 ). On the face, the most affected region was the eyes (31.4\%

Table 1. Data from Physical Violence against Children and Adolescents (PVCA) between 2009 and 2013 in Porto, Portugal

\begin{tabular}{lcc}
\hline Sex & $\mathrm{N}$ & $\%$ \\
\hline Female & 601 & 43.6 \\
Male & 779 & 56.4 \\
& & \\
Age & & \\
0 to 14 & 611 & 44.3 \\
15 to 17 & 769 & 55.7
\end{tabular}

Year of Occurrence

$\begin{array}{lll}2009 & 319 & 23.1 \\ 2010 & 288 & 20.9 \\ 2011 & 279 & 20.2 \\ 2012 & 252 & 18.3 \\ 2013 & 242 & 17.5\end{array}$

Medical Assistance

$\begin{array}{lll}\text { Yes } & 780 & 56.5 \\ \text { No } & 600 & 43.5\end{array}$

First Occurrence

$\begin{array}{lll}\text { Yes } & 1099 & 79.6\end{array}$

No $\quad 281 \quad 20.4$

Total

1,380

$100 \%$ 
of the injuries), followed by the mouth and nose (Fig. 1).

Regarding sex, the face displayed more injuries in both sexes (males: $36.8 \%$; females: $28.6 \%$ ), being the differences statistically significant ( $p=0.001$ ), when age was analyzed, no statistically significant differences were observed, being the face, once more, the most affected area (Table 4).

The eyes, mouth and nose are, in order, the most likely regions affected by physical aggression to the face. These three regions together are responsible for $81.2 \%$ of all facial injuries. Teeth and/or lips were struck in 179 cases (56 lips, 27 teeth and 96 teeth and lips), teeth injuries were described as avulsions, fractures or dislocations (Table 5, Fig. 1). The remaining 25 cases were described as only reached the mouth region. In INMLCF-DN the expert examinations are performed by medical, there are no dentists in their staff. The dentist is only called to the service when the judicial authority summons for further detail of the case. Consequently, many cases do not have a detailed description of the dental lesions.

The lapse of time between the aggression and the examination in INMLCF-DN had a median length of 2 days (SD 58.99, a minimum of 0 days and a maximum of 718 days).

Offenders were categorized into two groups, namely, offenders known to the victim (father, acquaintance, colleague, mother, relatives, neighbor, stepfather, companion, teacher, stepmother, and caregiver) and offenders not known to the victim (strangers and figures of authority). The sum total of known offenders represents $77.1 \%$ of all alleged aggressors.

\section{Discussion}

In the five-year period used in the survey, 2,148

Table 2. Injured body regions in 1,380 victims

\begin{tabular}{lcc}
\hline Body region & $\mathrm{N}=3,019$ & $\%$ \\
\hline Skull & 433 & 14.3 \\
Face & 747 & 24.7 \\
Neck & 203 & 6.7 \\
Collar bone/spine & 65 & 2.2 \\
Chest & 305 & 10.1 \\
Abdomen & 92 & 3.0 \\
Pelvis & 4 & 0.1 \\
Right arm & 381 & 12.6 \\
Left arm & 356 & 11.8 \\
Right leg & 202 & 6.7 \\
Left leg & 231 & 7.7 \\
\hline
\end{tabular}

records of charges of violence were evaluated of which 1,380 showed a causal link between the charge of physical aggression and injuries present on the complainant's body. There was a decrease in the number of occurrences during the five-year period studied. Among the practices that may have led to this result, preventive actions can be cited which were implemented by the governmental body called the National Commission for Protecting Children and Young People at Risk (CNPCJR in Portuguese) which is responsible for public policies on children and adolescents alongside with the Commissions for Protecting Children and Young People (CPCJ in Portuguese) which are non-judicial official institutions with functional autonomy that seek to promote the rights of children and young people.

As for the 768 cases for which no link was attested, it cannot be stated that there was no aggression, but rather

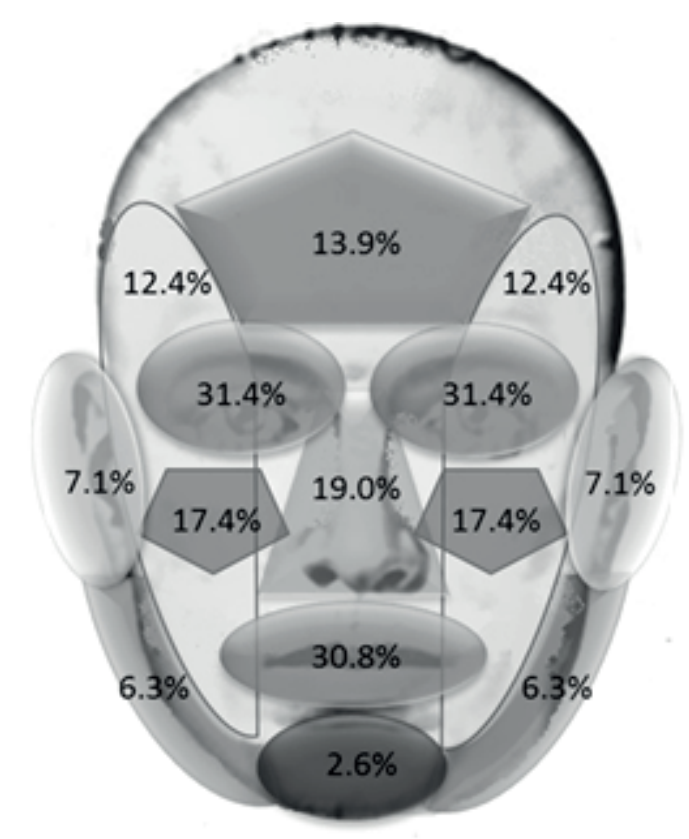

Distribution of lesions of the face.

Table 3. Distribution of injuries to the head, face and neck by body region

\begin{tabular}{lccc}
\hline Body region & Cases & Injuries & $\%$ \\
\hline Head & 164 & 164 & 11.9 \\
Face & 459 & 459 & 33.2 \\
Neck & 69 & 69 & 5.0 \\
Head and face & 192 & 384 & 27.8 \\
Head and neck & 38 & 76 & 5.5 \\
Face and neck & 57 & 114 & 8.2 \\
Head, face and neck & 39 & 117 & 8.5 \\
\hline
\end{tabular}


simply that this could not be confirmed in the clinical or laboratory test conducted on the complainant. Two factors act directly together which result in hindering observing signs of violence: the lapse of time between the aggression and the examination, and the intensity of the acts of aggressions that sometimes are so subtle that they leave no traces of physical evidence (17). Injuries such as bruises can provide important and consistent information about the time that has elapsed since the aggression because they have a chromatic evolution in which: red or blue bruises are signs of injuries that occurred within the previous 1-3 days; yellowish green ones 4-7 days prior and yellowish brown 8-26 days prior to the examination (17).

In cases in which there was a longer lapse of time between the occurrence and the completion of the report, there is a relationship with the cases where the complainant received medical care after the aggression or when the process was started late or, even, when additional tests were requested, thereby prolonging the period it took to complete the report. Medical and dental assistance shortly after the occurrence of aggression is extremely important in order to establish causation and minimize the loss of the characteristic sings of the assault due to the delay between the incident and the forensic examination.

Analysis of the data demonstrated that adolescents are physically abused more often than children, thus corroborating the findings of Bernardino (18). From the age of 15 , a considerable increase was observed in the number of aggressions and this can be explained by the

Table 4. Distribution of injuries to the head, face and neck by sex and age

\begin{tabular}{|c|c|c|c|}
\hline & Region & $\%$ & Chi-square \\
\hline \multirow{3}{*}{ Male } & Head & $9.9 \%$ & 0.009 \\
\hline & Face & $36.8 \%$ & 0.001 \\
\hline & Neck & $5.6 \%$ & 0.208 \\
\hline \multirow{3}{*}{ Female } & Head & $14.5 \%$ & 0.009 \\
\hline & Face & $28.6 \%$ & 0.001 \\
\hline & Neck & $4.2 \%$ & 0.208 \\
\hline \multirow{3}{*}{$<15$ years old } & Head & $12.9 \%$ & 0.285 \\
\hline & Face & $32.4 \%$ & 0.548 \\
\hline & Neck & $4.9 \%$ & 0.891 \\
\hline \multirow{3}{*}{$\geq 15$ years old } & Head & $11.1 \%$ & 0.285 \\
\hline & Face & $33.9 \%$ & 0.548 \\
\hline & Neck & $5.1 \%$ & 0.891 \\
\hline
\end{tabular}

greater autonomy that young people acquire as they get older, both in terms of their reporting possible cases of domestic violence, and because they experience greater social exposure in schools, shopping malls and public places (19).

On analyzing the frequencies of injuries and their distribution all over the bodies of the victims, the face and head are the areas most often affected, followed by the arms. Together injuries to the head, face and neck which accounted for $45.1 \%$ of body injuries were studied separately from injuries to other regions of the body. The face is most commonly struck due to the process of subjugation and humiliation inherent in the character of aggression while injuries to the arms are associated with the victims' attempts to defend themselves from acts of aggression $(6,20)$, finding that is in accordance with other studies $(4,17,18,21)$ because of its vulnerability and of the psychological impact and these relate to the process of subjugating the victim to the aggressor's will $(4,22)$. When injuries by gender are compared, the face remains the region most affected, boys being subject to a greater number of acts of aggression than girls. On analyzing injuries by age group, no major differences were found between those less than 15 years old and those who were 15 years old or older $(18,23)$.

The mouth was the facial region mostly affected by aggression. This is very often cited by some authors and these injuries result from the forced introduction of an object in the mouth or on trying to silence the child. Injuries to the mouth, the space between the gums and lower lip and the floor of the mouth when one tries to force a child to eat and are also suggestive of attempted sexual abuse $(9,11)$. Other authors also mention that injuries to the lip or tongue brakes are normal in a child who is learning to

Table 5. Regions affected on face reported by medical examination

\begin{tabular}{lcc}
\hline Region & $\mathrm{N}=662$ & $\%$ \\
\hline Eyes & 208 & 31.4 \\
Mouth & 204 & 30.8 \\
Nose & 126 & 19.0 \\
Zygomatic arch & 115 & 17.4 \\
Front & 92 & 13.9 \\
Hemiface & 82 & 12.4 \\
Ears & 47 & 7.1 \\
Jaw & 42 & 6.3 \\
Mental & 17 & 2.6 \\
Temporomandibular joint & 6 & 0.9 \\
\hline
\end{tabular}


walk and accidentally falls (between 8 and 18 months old). When these injuries occur in younger or older children, they are highly suggestive of abuse $(9,11)$. When a dental trauma occurs, this preferentially involves temporary front teeth, and is often caused by direct trauma (by a fist or hand) or indirect trauma (a heavy instrument which has been thrust into or on the oral cavity) (24). Dental trauma includes fractures, dislocations or subluxation, or the unexplained absence of teeth $(9,11,23,25)$.

Health professionals in hospital emergency departments and those in the private sector can, in their daily activity, play an important role in detecting PVAC. The increasing public awareness regarding the importance of oral health lead youngsters to dental offices more often. This fact allows dentists to have a better chance at identifying suspicious signs of aggression towards children and adolescents $(7,8)$.

The link of causality between the complaint and the aggression was high, this being confirmed by medical examination in INMLCF-DN. Adolescents were more frequently victims than children. The region of the victim's body that was mostly affected by physical aggression was the face. Injuries to the face were more prevalent in male patients than in female victims. Because dentists are the

first to act on these regions, they may be the professionals most equipped to make an early diagnosis of physical violence against children and adolescents (PVCA).

\section{Resumo}

0 objetivo deste estudo foi verificar a prevalência de atos de agressão à cabeça, face e pescoço em relação às vítimas de Violência Física contra Crianças e Adolescentes (PVCA) que foram examinadas no Instituto Nacional de Medicina Legal e Delegação de Ciências Forenses Norte (INMLCF -DN) no Porto, Portugal. Um estudo foi realizado em 2.148 queixas de agressão física contra crianças e adolescentes [0 a menores de 18 anos] ocorridas entre 2009 e 2013 e que foram recuperadas de informações sobre violência mantidas em arquivos de dados do INMLCF-DN. Variáveis contínuas foram descritas para verificar a suas correlações foram usados os testes do Chi-Quadrado e o Teste Exato de Fisher em um nivel de significância de $5 \%$. Nestes 5 anos, foram detectados 1.380 casos que apresentam nexo clínico com agressão física. As vítimas mais acometidas eram adolescentes do sexo masculino, a região do corpo mais atingida foi a face com 747 das lesões $(24,7 \%)$ registradas. Há significância estatistica no teste do qui-quadrado de Pearson na relação de gênero com a cabeça e o rosto. Dentistas rotineiramente examinam o crânio, rosto e pescoço que os torna os profissionais mais adequados para identificar casos de agressão precoce. Os adolescentes são mais suscetíveis à violência do que as crianças menores de 12 anos.

\section{Acknowledgements}

The authors thank the INMLCF-DN (Instituto Nacional de Medicina Legal e Ciências Forenses - Delegação do Norte, Portugal) for technical support and CAPES (Coordenação de Aperfeiçoamento de Pessoal de Nivel Superior, Brazil) for scholarship. and health: summary. Geneva, World Health Organization, 2002.

2. Rao $S$, Andrew LL. The epidemiology of child maltreatment. Paediatr Child Health 2012;22:459-464.

3. Pelisoli C, Pires JPM, Almeida ME, Dell'Aglio DD. Sexual violence against children and adolescents: data from a referral service. Temas Psicol 2010;18:85-97.

4. Rabello PM, Caldas Júnior AdF. Facial Lesions of woman who have been physycally attacked - Paraiba - Brazil. Odontol Clin Cient 2007;5:5.

5. Crespo M, Andrade D, Alves A, Magalhães T. The role of the dentist in the diagnosis and signaling of child abuse. Acta Med Port 2011;24:939-948.

6. Brink 0 . When violence strikes the head, neck, and face. J Trauma 2009;67:147-151.

7. Mouden L. Family violenceb prevention: dentistry's attitudes and responsabilities. Quintessence Int 1998;29:452-455.

8. Darche V, Delheusy G, Demars-Fremault C. Le syndrome de Silverman en odonto-stomatologie. Act Odonto Stomatol 1997;199:479-490.

9. Welbury $\mathrm{R}$, Murphy J. The dental practitioner's role in protecting children from abuse. 2- The orofacial signs of abuse. Br Dent $\mathrm{J}$. 1998;184:61-65.

10. Persaud DI, Squires J. Abuse detection in the dental environment. Quintessence Int. 1998;29:459-468.

11. Vaillant P. Les sévices envers les enfants. Rôle de l'odontologiste. . Act Odonto Stomatol 1997;199:479-490.

12. Caldas IM, Magalhaes $T$, Afonso A, Matos E. The consequences of orofacial trauma resulting from violence: a study in Porto. Dent Traumatol 2010;26:484-489.

13. Magalhães T, Ribeiro CS, Jardim P, Vieira DN. Forensic procedures in the scope of information collection, physical examination and harvesting of traces in children and young victims of physical and/or sexual abuse. Acta Med Port 2011;24:339-348.

14. Barreto CSLA, Araújo RPC, Martins Júnior DF. Epidemiological study of violence against children according to the records of the Information System for Notifiable Grievance - SINAN, Bahia, Brazil - 2008 to 2012. R Ci Med Biol 2012;11:140-148.

15. Gabatz RI, Padoin SM, Neves ET, Terra MG. Factors associated with institutionalization: perspectives for children who suffered domestic violence. Rev. Gaucha de Enferm 2010;31:670-677.

16. McDowell J. Diagnosing and treating victims of domestic violence. N Y State Dent J 1996;62:36-42.

17. Herrera LM, Serra MdC, Fernandes CMdS. Violence against children and adolescents: the importance of knowledge of the spectrum of bruise colors in its diagnosis.: RSBO; 2013. p. 378-385.

18. Bernardino İdM, Barbosa KGN, Nóbrega LM, Cavalcante GMS, Silva JAL, d`Àvila S. Physical violence against Brazilian children and adolescents: a 4-year study. J Public Health 2016:1-6.

19. Marysko $M$, Reck $C$, Mattheis $V$, Finke $P$, Resch $F$, Moehler E. History of childhood abuse is accompanied by increased dissociation in young mothers five months postnatally. Psychopathology. 2010;43:104-109.

20. Thube $H_{1}$ Chikhalkar $B$, Nanandkar S. A Prospective study of injury pattern in victim of assault attended in South Mumbai government hospital. J Indian Acad Forensic Med 2015;37:37-40.

21. Valente LA, Dalledone $M$, Pizzatto $E$, Zaiter $W$, de Souza JF, Losso $E M$. Domestic violence against children and adolescents: prevalence of physical injuries in a southern Brazilian metropolis. Braz Dent J 2015;26:55-60.

22. Rabello PM, Caldas Jr AF. Violence against women, family cohesion and drugs. Rev Saude Publica 2007;41:970-978.

23. Flynn-O'Brie, KT, Rivara, FP, Weiss NS, Lea VA, Marcelin LH, Vertefeuille $J$, et al. Prevalence of physical violence against children in Haiti: A national population-based cross-sectional survey. Child Abuse Neglect 2016;51,154-162.

24. Le Heuzy M. Le point de vue d'un psychiatre d'enfants et d'adolescents. Act Odonto Stomatol 1997;199:503-507.

25. Haugh R, Foss J. Maxillofacial injuries in the paediatric patient. Oral Surg Oral Med Oral Pathol Oral Radiol Endod 2000;90:126-134.

\section{References}

1. Krug E, Dahlberg L, Mercy J, Zwi A, Lozano R. World report on violence
Received August 8, 2017 Accepted November 28, 2017 